The role of ICTs in everyday mobile lives

\title{
The role of ICTs in everyday mobile lives
}

\author{
Tilly Line, Juliet Jain, and Glenn Lyons
}

Centre for Transport \& Society, University of the West of England, Bristol, UK 


\section{Research highlights}

- ICTs are incidental rather than instrumental in shaping social practice and travel

- ICTs contribute to and compensate for unpredictability in activity scheduling

- Absorption of ICT-related practices into lifestyles prevails over creative behaviour 


\title{
The role of ICTs in everyday mobile lives
}

\begin{abstract}
Information and communications technologies (ICTs) are permeating modern lifestyles, shaping and colouring the undertaking of activities and travel. This article reports on a qualitative diary and interview study that explored the ways in which ICTs are being used by students aged 18-28 and part time working mums. Study participants were selected on the basis of being 'informal experts' reflecting their affinity for engagement with ICTs. Through an exploration of the interview findings, it becomes clear that relatively new technological devices and applications have quickly become embedded into the participants' everyday travel and communications. Changes in social practice at the level of the individuals are not visibly dramatic, but at the same time, there is evidence of a cumulative influence of ICTs on their daily lives. Technologies are enabling the participants to better accommodate the uncertainties in activity and travel scheduling and yet also contributing to a 'fluidity' in time-space co-ordination of activities. They are also allowing the juggling of life roles in time and space leading to apparent fragmenting of activities. The article reflects upon the travel behaviour consequences of ICTs in their influence on everyday life.
\end{abstract}

Keywords: ICTs, social practice, travel behaviour, innovation 


\section{The role of ICTs in everyday mobile lives}

\section{Introduction}

Travel behaviour increasingly faces being influenced by information and communication technologies (ICTs), notably in the way everyday activities are ordered, managed and completed. The reshaping of time-space practices and opportunities afforded by ICTs has prompted wide reaching research in this area, as indicated below. In our research we have been concerned with the potential for innovation to be stimulated in response to addressing particular transport related 'problems' that may form part of people's everyday lives. How might individuals be creating and engaging in new ways of doing things to overcome some of the mobility challenges they face? This paper builds on the diverse literatures surrounding ICTs to consider how travel and communications are situated in broader daily activities.

ICTs may have 'conquered' space, but people still travel; however, in the 'networked society' the relationship between ICTs and travel is changing how and when people meet or communicate (Castells, 2000). Specifically Schwawen and Kwan (2008) explore the reconfiguration of time-space geographies through ICTs (i.e. the internet and mobile phone), demonstrating the ways in which individuals select from a range of 'tools' (e.g. car, bicycle, internet, phone) to manage relationships between home and work, provide different forms of access (in time and space), and enable new possibilities for multi-tasking; (noting this reconfiguration often has a gendered element). ICTs, especially mobile phones and wifi, have facilitated a more mobile corporeal relationship with space, including micro-cordination and rescheduling on the move (Rheingold, 2003; Townsend, 2000), and lifting activity (e.g. 
work) out of place (e.g. the office) to distributed locations, including those on the move (e.g. Lyons et al 2007), creating what Couclelis (2000) calls 'activity fragmentation'. The examples of combining teleworking into the working day and on-line 'window shopping' combined with actual shopping trips discussed by Lyons et al (2008) is indicative of the concept of fragmentation, and recognises that there many obligations or desires to be co-present remain (Urry, 2004)

Couclesis (2009) hints there may be social hierarchies in who has the power to be flexible in time-space. However, the pushes and pulls of fixity and flexibility should not always be considered solely in the workplace. Those whose employment (or study) may be fixed in time-space by others, may also utilise a range of ICTs and corporeal mobility to manage competing demands and responsibilities within and beyond the workplace. Thus, it is possible to assume that across social groups where people have embraced ICTs into their personal lives it is tenable that "people are taking advantage of the newly available opportunities in creative and often unexpected ways" (Couclelis, 2009) to address the time-space tensions and 'problems' across everyday life, which may influence their resultant transport behaviours.

This paper adds further weight to such discussions of ICTs and travel behaviour by focusing on the social context in which choices to travel or use ICTs are made and enacted. Specifically, the discourses generated by the qualitative examination (through a diary-interview study) of the intersection and layering of ICTs and travel adds to the social richness of these debates. The methodological approach taken also provided a context to explore where and why there might be opportunities for 'innovation' to occur or be incorporated by the individual in response to transport 
challenges that might arise in managing the time space connections demanded by home, work, study etc.

Innovation here is taken to mean novel or creative uses of material artefacts (e.g. mobile phones, computers, etc) and/or services (e.g. web services, iPhone Apps) that impact upon social practice. Innovation can relate to society as a whole or apply at the level of an individual (in that a person is encountering artefacts and/or services that are new to them and which impact upon their own social practice). Borrowing from Von Hippel's explanation of ‘user innovation' (see ‘Democratising Innovation', 2005) we assume that such innovation is motivated by seeking a solution to a particular problem. Like all innovations the social context is central to the diffusion of user innovations (Rogers, 2003).

The core concerns of the research explored in this paper were thus:

i) how ICTs become embedded in the practice of everyday mobility,

ii) the degree to which the participants' everyday mobile lives provide motivation for, or enable, innovative (or 'creative'), use of ICTs.

The paper begins with an outline of the methodology used and the justification for this approach in which we use two case study participants as exemplars to lead us into the wider findings across our groups of participants. The findings are situated in three concepts of the intersection of ICTS, travel and everyday life: i) the social embedding of ICTs; ii) social network maintenance; and iii) connectivity on the move. In each case the findings are discussed in relation to existing literature. Through these three themes we explore some key issues for travel behaviour and assess to what extent novel use of ICTs could exert influence. 


\section{Methodology}

Using an exploratory, qualitative, approach we aimed to research the use of ICTs by 'informal experts'. Their expertise relates to personal interest rather than the formal knowledge from a professional relationship with technology such as web design. Informal experts here refer to people who have a good grasp of the range of functions on their mobile phone, probably use a Personal Digital Assistant (PDA), BlackBerry, or similar, easily find their way around the Web, and participate in some online interest group or social networking site - people who tend to enjoy using technologies and have an interest in the emergence of new ICTs into the market. They were sought on the basis that they would have a richer engagement in comparison to the public at large with ICTs and in some senses be more likely to reflect early adopters (Rogers, 2003) of emerging trends in ICTs use.

Two particular groups were chosen: 'Mums who work part time' and 'University students'. Thus we recruited 11 mums working part-time in a variety of jobs, with 1-3 children aged 0-18 years, and 5 male and 5 female undergraduates aged 18-28), studying at the University of the West of England, Bristol.

Although the participants, even within the two groupings, may seem diverse, we were not attempting to recruit a representative sample in order to discover 'truths' about these societal groups, nor were we trying to compare them in order to find 'significant differences'. Instead we aimed to recruit a 'purposive sample' of individuals likely to face particular mobility challenges as it is these challenges that may motivate use of ICTs in creative, or 'innovative' ways. Thus, 'Mums who work part time' were recruited on the basis that they are identified within the literature as a 
particularly time constrained social group, especially with regard to juggling work and children's time commitments where the car often becomes the solution (e.g. Davies, 2001, Skinner, 2003, Dobbs, 2005, Schwanen 2008b). 'University students' were chosen on the basis that firstly, young people are at the cutting edge of mobile technology and internet use and integrating it into the organisation and maintenance of social networks (Green, 2002, Thulin and Vihelmson, 2007, Herring, 2008, Livingstone, 2009) and secondly, students have, or are in the process of adjusting to life in a new city and establishing, new social networks. Thus students, provide an interesting layering of maintaining long distant relationships with family and former friends, and forging and maintaining new local social networks. The students were recruited via distribution of leaflets, posters and verbal advertising after lectures and the Mums were recruited through 'Netmums' (an online forum), a press release, and an advert at a local school.

In light of the challenge of uncovering the complexities of everyday mobile life, exploratory, qualitative methods were chosen. Data was generated using a one day diary and a follow up interview ${ }^{1}$. As Kenyon (2006) writes, the use of diaries is not unusual in travel behaviour research, yet they are traditionally used to capture the 'specifics' of travel; the origin of the trip, time of departure, number of the bus caught etc. Here we are more interested in the narrative of daily life as mapped out by the participants and by allowing the participants 'room' to represent their day in a range of different ways (using pen and paper, a computer, photographically, in music), rather than accurately quantifying specific time-space activity durations. The diary acted as tool in facilitating a broader discussion during the interview about the organisation of the participant's everyday life, transport and ICT use, and to uncover 'problems' or challenges faced. This approach drew on the use of visual 
methodologies within human geography, notably Latham's photography diaryinterview methodology (Latham 2003, 2004) in which he refers to the importance of such creative, performative practices (rather than "conventional, representationally orientated" methods), in understanding the embodied practice of everyday life. This approach enables the participant and the researcher to more easily situate themselves in the day being recalled during the interview - something that Buscher and Urry (2009: 106) note "would be difficult to construct through unaided reflection".

On receiving their diary pack, the participants were asked to complete an account of travel, phone and email communications, websites visited and activities undertaken (e.g. work, university work, collecting kids from school) for one day². They were provided with the diary (designed as an A2 sheet folded into an A5 leaflet) which includes information about the research, what to do and a consent form; a disc for saving electronic material (e.g. digital photos, audio diary etc); pens; a glue-stick; and a disposable camera. As such, they were encouraged to express themselves - to not only write, but to draw pictures, stick on bus or train tickets, verbally record a diary, or create a track list of their favourite music to travel by. Several people took photos which were developed by the researchers and discussed along with the diary during the interview. The interviews lasted 1-2 hours and explored the participants' broader use of ICTs, travel and everyday activities, tailored around the participants' individual diaries but along common themes. These themes reflected the core research concerns noted in Section 1 and thus each participant was typically asked the following questions:

- What is your job / what course are you studying?

- What hours do you work / study? 
- What technologies do you typically use and how do you use them (for work or university activities, personal activities and to keep in contact with friends and family)?

- How would you feel if you lost your mobile phone or could not connect to the internet?

- What modes of transport do you use, when and why?

- $\quad$ How do you spend your time when travelling and how does this differ by mode?

- $\quad$ How do you obtain travel information via different ICTs?

- $\quad$ (If they drive) What role does the car play in your life?

- What role do ICTs play in meeting your life aspirations?

- What problems or challenges do you face in organising your day (particularly in relation to travel) and how might technologies be used to solve them?

\section{Insights and interpretations}

\subsection{Introduction}

The diary and follow up interview reveal a complex coming together of corporeal travel and virtual communication across the daily lives of the participants. The discussion of the findings from the two groups spans all study participants. However, it is framed by two 'case' diaries/interviews reflecting one of the mums (Anna) and one of the students (Ingrid). The intention is that this helps to: (i) acquaint the reader with the types of diary data gathered; (ii) demonstrate the link between the diary and the interview data; and (iii) demonstrate the importance of individual 
discourses. Anna and Ingrid $^{3}$ were chosen because they both enjoyed using a range of technologies and applications.

\section{$\underline{\text { Anna }}$}

From the Mums group, Figure 1 illustrates the diary produced by Anna (she also provided a series of photos that accompanied this). Anna is 40 years old and has three children. She commutes to work by bicycle and occasionally by car and her husband commutes by bicycle. Anna uses her mobile phone to text, call, take and store photos and as a diary. She uses the internet at home and at work to email, search for information and watch TV on a daily basis. She referred to her love of gadgets, in particular her mobile phone.

Ingrid

Figure 2 is a photo of the diary produced by Ingrid, a 20 year old student in her second year of university study. She rents a room in a large student house near Bristol city centre and commutes to her place of study by bus. Ingrid, can drive but cannot afford to run a car while she is studying. She is a regular user of her mobile phone to text and call, and the internet at home and at university for information searching, email and social networking sites. She is a particularly keen user of Facebook ${ }^{4}$.

The research methodology allowed participants to illustrate how travel and communication are combined within and encompassed into everyday life which supports wider debates within travel behaviour and 'mobilities' research (e.g. Larsen et al., 2006, Schwanen and Kwan, 2008). Subsequently, our findings in this paper are oriented around two core debates: 
1. ICTs, mobility and communication - both 'at a distance' and 'face-to-face'; and

2. ICT use 'on the move'.

These debates represent two key dynamics of mobility in the context of ICTs the first relating to the mobility of (ICT based) information both at a distance and in person and the second to the mobility of people. Clearly, the coming together of people for work, education, fun, etc, remains a function of everyday life, despite the opportunities to substitute such face to face encounters through electronic means (Urry, 2004). Yet, virtual mobility and communicating at a distance is layered into activities across numerous locations, and, on the move as indicated in the introduction (e.g. Laurier, 2002; Kenyon and Lyons, 2007; Lyons et al., 2007, Schwanen and Kwan, 2008, Coucelis, 2009). Thus, in order to explore the intersection of ICTs, travel, and everyday life, we have orientated our arguments around these two themes. The first theme situates our research participants in their various places - home, work, education. It then considers the role of ICTs in relation to these place contexts and the degree to which this may provide an 'acceptable' substitute for face-to-face communication (Lyons et al, 2008a). Focusing on the journey, the second theme considers how mobile spaces are inhabited in relation to technologies.

3.2. ICTs, mobility and communication 
Places of employment and education, and increasingly homes, are networked hubs through which virtual and corporeal connections flow in and out (Castells, 2000). Virtual flows often augment corporeal mobility rather than directly replacing it, as this section demonstrates. Having access to the internet, for example, in multiple locations (and on the move, see 3.3. below) enables activities to be distributed across a number of spaces rather than being spatially contained, thus enabling a change in the dynamic of activities across time too. Coucelis' (2009) concept of 'fragmentation' becomes poignant reflecting ICTs' loosening of spatial and temporal boundaries, which Hubers et al. (2008: 528) summarise as 'a process whereby a certain activity is divided into several smaller pieces which are performed at different times and/or locations'. The qualitative approach of this research connects such distribution with individual identity and the social context of being connected.

\subsubsection{The embedding of ICTs in work and social networks}

Participants illustrated the degree to which the use of ICTs for communication has become socially embedded for work and study, as well as for maintaining social networks and the management of time.

From home Ingrid downloads her lecture notes prior to attending lectures in person $^{5}$. Like the other students, she also checks for lecture and seminar times and possible cancellations, as well as exam results online or via email, assessing whether she needs to travel to university at all. In this sense the internet acts as the 'middle man' between students and staff, removing the need for constant face to face 
interaction and constituting an easy way for 'many to one' and 'one too many' communications.

Anna, and the majority of other Mums, in particular talked about the role of the mobile phone in affording last minute changes in travel arrangements, predominantly in relation to being asked, or asking others, to collect/hold children when they are caught up at work or in traffic,

“...if it looks as though I'm going to work late I have to ask my husband to leave work early to collect the children full stop, or I'll ring the child-minder and she might collect the child from school and then keep the child" (Anna, part-time working mum)

The ability to reschedule via the mobile phone has changed the travel experience. Laurier's work on mobile sales personnel demonstrates how the mobile phone has been assimilated into schedule management; notably affording rescheduling as delays occur along the route (Laurier 2002). For the mums, being able to phone into work or re-arrange child pickups from school facilitates the possibility of driving at the edge of time (i.e. time margins for contingency are less necessary). Reiterating the findings of others (Schwanen, 2008; Bonsall, 2004), the mobile phone is thus identified as a vital tool when it comes to juggling work and family commitments. In turn it plays a part in enabling mothers to return to work with consequences for transport system use.

The ability to communicate last minute information via mobile phones was also referred to as useful when discussing train time text alerts or calling traffic information phone lines. Although transport providers are also now using Twitter ${ }^{6}$ to 
provide the public with real time travel information (see RAC, 2009; Nationalrail, 2009), it's rapid rise in popularity happened after the collection of our data (October 2008 to January 2009) - although one student mentioned using it to communicate with friends. This reflects the degree to which society is in a period of transition when it comes to ICT use, although the success of applications (such as Twitter) in this context remains to be seen.

In contrast, participants from all groups referred to their irritation at mobile phones allowing people to cancel plans at the last minute, or to make no 'concrete' plans at all ${ }^{7}$.

\author{
"I reckon it's a bit more disposable, people can change their minds a lot \\ easier. I know I have before, I've been at home and said I'm going for a drink \\ with someone, and then at the last minute just sent them a text, not even \\ phoning, it was a bit rude really." \\ (John, student)
}

Thus it seems ICTs are on the one hand helping people accommodate uncertainty and yet at the same time eroding the fixity of schedules and arrangements and in turn contributing to uncertainty. Consequently, there may be a circular process of uncertainty fuelling reliance on ICTs that consequently generates further fluidity and in turn uncertainty and a further reliance on ICTs.

But what does this mean in terms of travel behaviour - that people travel more, less, or that there is more spontaneous travel? It rather appears for our participants that instead technologies have simply been absorbed into their everyday lives and although they can obtain real time information, ask someone else to pick up 
their children or cancel plans at the last minute, their actual travel behaviour has not fundamentally changed - they still commute to work by train but at a later time, drive to pick up their children from a neighbour's house rather than school, and meet up with their friends another day. Our findings also suggest that mainstream use of ICTs (e.g. making of mobile phone calls) allows people to remove some of the challenges of travel, thus removing potential motivation to use technologies in more novel or innovative ways.

\subsubsection{Blurring of boundary spaces}

In many ways, ICTs have led to the blurring of boundary spaces between home and place of work or study. Via the internet and email Anna connects to her workplace in her home space, while also undertaking 'personal' activities at work, including her parenting 'duties' via her mobile phone. Many of the mums blur these boundaries by using work time for personal information searches (holidays and shopping), looking at /contributing to social networking sites (where allowed), as well as checking or sending personal emails. Two mums identified this as a good time to do such activities because there were no interruptions from children or their spouse.

It was evident that having a home computer and internet access enabled both Anna and others to manage their part-time work commitments outside of work time and space. Anna's quote below exemplifies the benefit of such out-of-hours work to her ability to feel in control, although there is also a sense of frustration. 
“...on a Sunday evening I always check my stuff from work, it's a bit of a bugger really because if I didn't have internet at home I wouldn't do it (laughs). ...I do get told off for doing it sometimes as well.

(Later)

...nobody really understands that part-time workers work part-time, they still expect as much out of you as possible, you still need to walk through the door at nine-thirty on a morning totally focused, bang, like that, and you can't be, if I haven't worked since Wednesday at two o'clock how the hell can I walk in the door Monday at nine-thirty and know exactly what's been going on and give an answer like that (clicking fingers) to the boss, I can't. So that's why I check stuff."

(Anna, part-time working mum)

In previous research into travel time use the journey was articulated as a preparation space between the home and work roles (and vice versa) (Jain and Lyons, 2008, see also Davies 2001). However, the interviews in this study indicate that preparation for the work role (in some instances) occurs in the home as well as on the move ${ }^{8}$.

As noted above, the mobile phone also enables home life to bleed into work life, being central to the 'constantly available' parenting role. While often the mums carry the mobile 'just in case' of accident or illness, those with teenage children issued with a mobile described how the apron strings of parenthood became extended through requests for PE kits and locker keys left at home, trivia or chitchat about nothing much. The challenge of being the employed parent who is constantly 'available' to the domestic sphere was acknowledged in the interviews. 
“... and he'll ring me at lunchtime, "hello mum, what are you doing, how's your day going, can I come home?" "No." So sometimes they're not such a good thing.

\title{
So he phones you at work?
}

Yes."

(Lucy, part-time working mum)

The blurring of space and place is different in the context of being a student, reflecting the greater number of spaces students routinely inhabit. For example, Ingrid talked about 'being a student' at university, at her home during term time and at home with her parents. In addition, the university itself has a series of distinct spaces - library, cafe/bar, classroom, project rooms etc and being a student is also about participating in student leisure activities (sport, clubs, quizzes, drinking, nightclubs) and living communally with other students, as well as studying. Thus it is a more holistic identity (than that of the part time working mums) that is diffuse across time and space - being a student is a constant state, as can be their online presence,

\author{
"I've got Skype open all the time and then Facebook. I'll go on every time I \\ want a bit of a break just to see who's online" \\ (Hannah, student)
}

Social belonging within the student groupings is dependent on technologies, from texting to Facebook. Their place within the university hierarchy is also virtually 
defined through specific online spaces for students, for communicating with lecturers and downloading course information as noted above. These virtual spaces have redefined the spatial boundaries of student life in recent years (Dutton and Loader, 2002; Reinhart, 2008). Again this illustrates society's growing dependence on technologies while also indicating that this dependence stems not from ICTs 'filling a gap', but from changes in the norms of communication and social practices such that to not be 'plugged in' would now render an individual comparatively excluded.

With respect to travel behaviour, these findings suggest that ICTs remove the need to be in certain places physically, when your presence can be felt virtually. In this sense there is perhaps less need to travel when you could work, study or be available for your children in one location via your mobile phone or computer. Nonetheless, students referred to the importance of face to face contact with lecturers and course mates,

\footnotetext{
"This whole thing about being with students and you know, you are telling each other your opinions and you are in the same mindset, so you are headed in the same direction. At home, everyone is doing other things, so you'd be just battling against yourself really. So I definitely think contact time at Uni is good."

(Daniel, student)
}

Ingrid also referred to her ability to submit coursework online, but her refusal to do so because she wants to "know it's been received" in person. Here Ingrid presents an issue of trust in relation to ICT substitution, which relates to the social 
context through which social practice 'normalises' ICT use, and in part facilitates the diffusion of innovation.

\subsubsection{Maintaining long distant \& local social network}

ICTs have become integral to the maintaining social networks, which can be seen as resources that enable the construction of 'a kind of connected presence' even when physically disconnected by distance (Licoppe and Smoreda, 2005: 321).

"I've got everything on [my mobile], everyone in my life really, you know right down to the builder's phone number"

(Anna, part-time working mum)

“...all of my friends are on [Facebook]. I do use it, I find it really useful and helpful just to keep up to date with what my friends are getting up to from home."

(Ingrid, student)

The choice of communication mode appears to have a type of hierarchy related to cost, who is being contacted, and the response speed demanded. In this research the mobile phone was found to be acting as the primary mode of communication. Lynne (part-time working mum) even suggested that, since having a child, she has become reliant on her mobile (texting in particular) to maintain her social networks. Both Ingrid and Hannah (students) referred to their use of video 
calls, through Skype, to keep in contact with family and friends who live a significant distance away and, in the case of Ingrid, to save money. Participants from both groups talked about using email in this context, but suggested it is secondary to the mobile phone as it is "impersonal", or because a greater proportion of their social network are more mobile or landline savvy than email savvy.

A number of the students referred to Facebook as a way to keep in touch with friends and family and share photos. Ingrid explained that it helped her to meet new people when she moved away from home to start her university course, reducing her feelings of isolation. She also explained that the Students' Union used Facebook to link up students with social events in the city centre during Fresher's Week. These students indicated that they had Facebook continuously open when using their computers, and would flick between Facebook and other applications to monitor activity. Thus, messaging via Facebook was preferred over email because of the immediacy of expected response.

In comparison to the students, Facebook is less integrated into the lives of the mums, although they also use it for sharing photos. It appears that they find it most useful for getting back in contact with old friends, rather than maintaining current friendships and relationships. Several of the mums pointed to time as the reason they do not use Facebook regularly, something that is less of a problem for the students who have fewer domestic demands and limits on access to Facebook ${ }^{9}$.

Here we question whether communication via the mobile phone and social networking sites (SNS) is likely to influence travel behaviour by acting as a substitute for face-to-face contact. Are people less likely to travel to see people socially because they consider communication via mobile phone and SNS an acceptable substitute? Previous research suggests this is not the case. According to Tillema et al. (2008), 
'corporeal travel in physical space does not decrease due to the ICT-mediated possibilities for maintaining social relations'. At the same time, research by Kenyon et al (2003) suggests that individuals use the internet to "supplement" existing travel, or as a substitute for an increase in travel.

In other words such ICTs-based communication enriches the access people have to other people without the need for yet more mobility (as opposed to replacing the need for mobility). In this sense ICTs have changed the ways in (or media by) which people communicate, but not the way they travel. Twenty years ago people were perhaps more likely to maintain long distant relationships via landline phone calls and handwritten letters, whereas now they may use email, text messaging or Facebook $^{10}$. However, it could be suggested that long-distant relationships are maintained through a combination of communication modes supported by occasional long-distance travel to enable face-to-face contact.

\section{3. 'On the move'}

Journeys are folded into the performance of roles, cultural interpretations of time, the shape of the urban fabric, the social shaping of technologies and the cultural mediation of technologies (e.g. the image promoted around phones, cars etc). Mobile technologies offer new ways for travel spaces to be inhabited; navigation on the move; and the re-organisation of schedules in real time (see for example Laurier, 2002; Brown and O'Hara, 2003; Jain, 2006; Lyons et al 2008b). In this section of the paper we explore how the data augments this growing area of literature, focusing on the constitution of the journey and how it is situated in relation to other activities and 
social interaction. It should be noted that although our participants were active users of a range of technologies, it was the mobile phone that always travelled with them, the MP3 player/iPod accompanied some, and the occasional laptop was taken on longer journeys (either for work or when visiting friends or relatives).

\title{
3.3.1. Inhabiting travel spaces
}

\author{
"So music's just... it's nice, relaxing. You can get into your own little zone" \\ (Ingrid, student)
}

Like many travellers, Ingrid uses her phone as an MP3 player when she travels by bus. It passes the time, but is limited in the number of tracks it can store. She uses it in preference to her iPod because she perceives the bus as a risky space, which she supports with media generated discourses.

"Yes, I've got an iPod as well but that's just another thing to carry and also any kind of valuable that you have out on display is going to be, you know, attractive to thieves or whatever... I saw the news the other day and there was... I can't remember, I think it was in London but there was a guy who was beaten over the head on the top of a double-decker bus for an iPod" (Ingrid, student)

Ingrid inhabits the bus somewhere between being in her own private world, augmented by personal music, and in shared public space. She has actively selected a 
way of passively enduring her commute to study, in much the same way that passengers have hidden behind the printed word for more than a century (Schivelbusch, 1980). She also inhabits it warily - conscious of potential danger associated from conspicuous consumption.

The concept of 'entertainment' or having 'something to do,' is indicative of cross-disciplinary research on the use of technologies and mobile experience (Jain and Lyons, 2008; Laurier and Philo, 2006; Burns and O’Regan, 2008). Other participants reiterated this technological passing of time - most notably using the mobile phone for idle interaction either as calls or text to defer boredom or more actively perceiving it as time to 'catch up' with others. So the travel space becomes inhabited as a social space; not social with physically proximate others, but social with others at-adistance.

The intersection of technologies and walking and cycling has received less attention than the passenger or even the car driver. Anna, however, tells us that she listens to her radio on her mobile phone during her cycle to work as it makes the journey more enjoyable, in the same way as she has it on when driving. Notably, amongst the student group generally, moving around is accompanied by music or radio.

"I will put on the radio as well, especially if there is some news going on I will listen to the news while I am cycling, just to use that time a little bit more." (Stella, student)

The effect of engagement with place, other than withdrawal on public transport or the personal space of the car, was not specifically alluded to by the 
participants - although evidence from other research in this area indicates that music can enhance an imaginative placing of the self - like being on a film set (Bull, 2000). However, there is little indication of how such entertainment particularly promotes one mode of transport over another, and indeed for Anna it is the same by bicycle or car, whereas Jain and Lyons (2008) indicate in comparing modes that the opportunity to work on the train can make it a more attractive mode than the car (as a driver).

Fewer people talked about walking and technology use, although notably Sarah (mum) demonstrated how use of her mobile phone can interweave with perceptions of safety and walking more confidently. She told us about walking to work and talking to her friend who was also walking to work but in another city. Prior to their adoption of this behaviour, her friend had been attacked while walking home and subsequently advised by the police that she was less vulnerable if seen talking on the phone.

Sarah (and her friend) and Ingrid use the phone as a tool of risk mitigation in different ways, but both as way of reducing personal attack in public space. The phone enables them to travel outside of the cocoon of the car and extend their opportunities to consume public spaces, thus suggesting an element of emancipation embedded in the phone.

Travelling, as a masculine practice, is infused with cultural assumptions about women's vulnerability that underpins the technological 'fix' of the mobile. Clearly, the notion of safety has given a gendered take on the mobile phone (Katz and Aakhaus, 2002). Many of the mums talked about their mobile phone being important for the just in case scenario of breaking down in the car or other difficulties, with words like 'security blanket' often being used to describe the phone. However, with 
this group the notion of safety extended beyond the self, immediate personal safety and being rescued, to managing the safety of their children at a distance.

In summary, travel spaces are inhabited in a number of different ways at the same time. The mobile phone and the MP3/iPod are not specific to travelling, but enable travel spaces to be inhabited in particular ways. Firstly, the travel space can be translated into a place of leisure that is disassociated with its physical setting. Secondly, they enable travel to be practiced more confidently in a cultural perception of fear. However, this theme of inhabiting space perhaps can be extended when discussing how technologies are also used to navigate on the move and for rescheduling purposes.

\subsubsection{Navigating on the move}

Neither Anna or Ingrid discussed navigating while on the move, but many other participants did. Mobile phones (with or without GPS) and in-car satellite navigation systems provided a sense of security for travellers, although frustrations with such systems were expressed. The mobile phone appeared once more to be a key assistant across modes.

Obviously in-car satellite navigation systems afford a specific in-situ tool, but not all car drivers like this technology or currently have it in their vehicles. Some described it as irritating or distracting, but others welcomed it. One mum, Lucy, previously had a car with an inbuilt 'sat nav' and had enjoyed the benefits it brought her. However, her new mobile phone had replaced the need to have a separate 
technology as it had an integrated GPS navigation system, which she occasionally used.

Other respondents brought up the accomplishment of navigation in a number of different contexts, which utilised different technological solutions but in fairly unremarkable ways. Debbie (mum) and Emma (student) described travelling in convoy for social and sports events. Debbie's son was in a football team that required his parents to spend their Sundays driving to different fixtures across Bristol and South Gloucestershire. Some parents chose to drive to the home club house and then onward in convoy, using mobile phones to communicate with the other car occupants if they became separated or needed to stop. Emma described a similar process in relation to reaching surf club destinations. However, she indicated that walkie-talkies were a cheaper option than mobile phones.

Seeking external help (i.e. beyond the vehicle) crosses modes. Stella, a first year student, described her trip to a training event for volunteers. She had taken the bus to the venue, which was in a part of Bristol unknown to her. Stella articulated a familiar story about the anxious anticipation of 'where to get off'. Her resolution of the situation could only be possible in an age of mobile communication and electronic maps.

"The First Bus's website sort of shows you a map of where the buses go, but it is not very clear, so I wasn't sure where to get off and as I was on the bus I was calling my Mum saying 'I am not sure where it is'. So she looked on Google maps for me...luckily she was in the library so she was on the internet at that moment. She was like 'I can help you' and I was like 'thank goodness", 
(Stella, student)

Stella clearly articulates the 'problem space' of relating stylised route maps to the on-the ground interpretation of location. Communication tools change possibility of navigation in-situ for passengers and drivers.

The development of the mobile phone continues to move it beyond being a device only for phone calls and texts with the offer of connectivity between people, entertainment, and access to information via mobile internet/GPS on the move across modes. In terms of travelling, the discourses of safety and emergency embedded in the rationale for carrying the phone suggest people travel more confidently (or even carefree), but any impact on modal choice needs further research. Likewise, despite being able to do ICT-enabled activities on the move, there is not the evidence here to indicate any impact on modal choice. However, it suggests that ICTs might ameliorate negative effects of a chosen mode and thus make it more bearable or attractive to keep travelling by the same mode. For instance the final example of Stella's wayfinding may demonstrate how individuals are removing the uncertainty from travelling along new routes (by whatever mode) through personal networks rather than seeking direct help from more 'official' sources.

\section{Discussion and conclusions}

As explained in Section 1, this paper reports on a qualitative, exploratory study of part time working mums and students, recruited on the basis that these societal groups are likely to face particular transport challenges (as guided by the 
literature). We did not aim to find truths about these groups and thus make 'generalisations' about them, but instead sought to understand common challenges people face in their everyday live and the degree to which these lead to the production or use of creative use of ICTs. With this in mind, the paper has illustrated the degree to which ICT use is strongly embedded into everyday mobile lives - augmenting (and in some cases blurring) social, study and work practices across different locations, allowing faster and more varied communication between friends, family, colleagues, course mates or lecturing staff. For the students it appears that the internet is particularly important, providing access to information about lectures and exams (often acting as 'the middle man' between the participants and university staff), as well as the ability to socialise with friends through social networking sites. For the part-time working mums it is clear that the mobile phone provides an especially useful tool for maintaining their social network, as well as their roles as an employee and mum.

The internet and the mobile are also used to obtain travel information, particular real time information like train time text alerts and traffic news. Mums use their mobile phones for last minute schedule changes such as rearranging child care, and the students talked about using the internet at home to check for lecture cancellations before leaving to travel to university. ICTs can therefore be seen to compensate for the unreliability or unpredictability in both the transport system and people's schedules of activities, although they can also add to unpredictability when people use mobile technologies to cancel plans at the last minute.

Despite their adoption by the participants, it appears ICTs are incidental, rather than instrumental when it comes to their social practice - both in relation to their social network (informal and formal) and travel. The ways in which the 
participants use ICTs can help them to deal with effects of the transport challenges they face (such as phoning a friend to pick up children when stuck in traffic, or phoning a parent to ask which stop to get off the bus), but they do not remove the challenges altogether. Most significantly however, it would appear that this is 'enough' for the participants as they do not seek solutions (including those that could be termed 'creative') beyond those provided by their mobile phone or the internet whether these are ICT based or not.

However, it can be argued that we are in a period of transition when it comes to the development and uptake of technology, as well the sustainability of the transport system. The cost of motoring may become more significant in relation to disposable income, environmental concerns may lead to policies and measures that more robustly encourage reappraisal of car use and a new technology savvy generation are entering the workplace (Palfrey and Gasser, 2008). We are also seeing an explosion in new applications available to (some) carriers of mobile ICTs epitomised by the 'iPhone apps' phenomenon.

We should not presume that ICTs are insignificant in their influence on patterns of travel and levels of travel demand. However, it is a challenging issue to investigate and understand. The diffusion of innovation (Rogers, 2003) is such that the changes in social practice and in turn travel afforded by ICTs are likely often to be gradual at the aggregate and cumulative over time: it can be difficult to pinpoint distinct impacts on travel behaviour attributable to particular advances. At the level of the individual from our own study we have been unable to identify what we would consider to be innovations in terms of ICTs use - especially in relation to travel. Individuals may well themselves sense innovation as they absorb new ways of using the ICTs at their disposal as either leaders or in most cases followers of trends in 
communication and social practice but it seems innovative behaviours quickly become 'everyday'. Compared to a decade ago perhaps we can say that much of what we have observed is innovative - certainly the opportunity to communicate at a distance while on the move - but in today's society it has quickly come to feel commonplace and, as we have already noted, while communications practices may have changed in this time, it is not so clear that travel behaviours are fundamentally changing. Instead it seems ICTs and their applications are lubricating modern life in terms of any aggravation and jarring of routines in time and space associated with the unpredictability or other disutilities of transport system use.

Methodologically we have illustrated the applicability of a qualitative, creative approach to studying transport geography by borrowing methods commonly used in mobility studies (see Fincham et al. 2010 for a discussion). By utilising a 'day in the life' diary we provided the participants with a creative space to capture their individual mobility challenges and enabled both the participant and researcher to more easily place themselves in the context being discussed during the interviews. Nonetheless, it is recognised that a further 'layer' of data could have been captured if we had carried out follow-up focus groups with the interviewees. As suggested by Freudendal-Pedersen et al. (2010), such an approach would allow exploration of the degree to which the participants' individualised insights are "negotiable or fixed in daily life" by challenging, confronting or opposing their views in a group environment.

In light of the findings presented here and with regard to future research in this area we suggest it is necessary to investigate the degree to which individuals' (or communities') transport 'problems' or 'challenges' act as motivation to change their travel behaviour and/or develop/use ICT based user innovations as a consequence. 
Such questions have important implications not only for the future prospects of user innovation but more widely in terms of endeavours to 'solve' people's transport problems - both at an individual, as well as a political level. There is growing recognition that people's decisions in relation to travel are often not rational or motivated by utility maximisation. Phenomena such as satisficing behaviour, bounded rationality and habit can contribute to strong inertia that resists behaviour change. A combination of this resistance and the incidental adoption of ICTs found in this study begs the question: whether user innovation holds any greater prospect of substantially influencing the travel behaviour of the population compared to that of 'top-down' efforts? 


\section{Acknowledgements}

The authors gratefully acknowledge the Engineering and Physical Sciences Research Council, the Department for Transport and the Technology Strategy Board as sponsors of the research addressed in this paper. The research forms part of the project 'Ideas in Transit'. 


\section{References}

Bonsall, P., 2004. Traveller behaviour: decision-making in an unpredictable world. Journal of Intelligent Transport Systems, 8, 45-60.

Brown, B and O'Hara, K., 2003. Place as a concern of mobile workers. Environment and Planning A, 35(9), 1565-1588

Bull, M., 2000. Sounding Out the City: Personal Stereos and Management of Everyday life. Oxford, Berg.

Burns, P.M. and O’Regan, M., 2008. Everyday techno-social devices in everyday travel life: digital audio devices in solo travelling lifestyles. In: Burns, P.M. Novelli, M., eds., Tourism and Mobilities: Local-Global Connections. Oxfordshire: CABI, 146-186.

Buscher, M. and Urry, J., (2009). Mobile Methods and the Empirical. European Journal of Social Theory, 12(1), 99-116.

Castells, M., 2000. The rise of the Network Society. Oxon: Blackwell.

Couclelis, H., 2009. Rethinking time geography in the information age. Environment and Planning A, 41, 1556-1575. 
Couclelis, H., 2000. From sustainable transportation to sustainable accessibility: can we avoid a new tragedy of the commons? In: Janelle, D., and Hodge, D., (eds) Information, Place, and Cyberspace: Issues in Accessibility. Berlin: Springer, pp 342356.

Davies, K., 2001. Responsibility and daily life reflections over timespace. In: May, J., Thrift, N. (eds.), Timespace: Geographies of Temporality. Routledge, London and New York, pp. 33-148.

Dobbs, L., 2005. Wedded to the car: women, employment and the importance of private transport. Transport Policy, 12, 266-278.

Dutton, W.H. and Loader, B.D. (eds.), 2002. Digital academe: the new media and institutions of higher education and learning. London: Routledge.

Fincham, B., McGuinness, M., Murray, L. (eds.), 2010. Mobile Methodologies. Basingstoke: Palgrave Macmillan, pp.193.

Freudendal-Pedersen, M., Hartmann-Petersen, K., Drewes Nielsen, L., 2010. Mixing Methods in the Search for Mobile Complexity. In Fincham, B., McGuinness, M., Murray, L. (eds), Mobile Methodologies. Basingstoke: Palgrave Macmillan, pp. 2542.

Green, N,. 2002. On the Move: Technology, Mobility, and the Mediation of Social Time and Space. Information Society, 18(4), 281-292. 
Herring, S.C., 2008. Questioning the Generational Divide: Technological Exoticism and Adult Constructions of Online Youth Identity. In: Buckingham, D., (ed.), Youth, Identity and Digital Media, The John D. and Catherine T. MacArthur Foundation Series on Digital Media and Learning. Cambridge, MA: The MIT Press, 71-92.

Hubers, C., Schwanen, T., Dijst, M., 2008. ICT and Temporal Fragmentation of Activities: An analytical framework and initial empirical findings. TESG Journal of Economic and Social Geography, 99(5), 528-546.

Jain, J., 2006. Bypassing and WAPing: Reconfiguring Timetables for Real Time Mobility. In: Sheller, M. and Urry, J., (eds.), Mobile Technologies of the City. Routledge: London and New York.

Jain, J. and Lyons, G., 2008. The gift of travel time. Journal of Transport Geography. 16, 81-89.

Katz, J., Aakhaus, M., eds., 2002. Perpetual Contact. Cambridge: Cambridge University Press.

Kenyon, S., 2006. The 'accessibility diary': Discussing a new methodological approach to understand the impact of Internet use upon personal travel and activity participation. Journal of Transport Geography, 14, 123-134. 
Kenyon, S. and Lyons, G., 2007. Introducing multitasking to the study of travel and ICT: examining its extent and assessing its potential importance. Transportation Research, 41(A), 161-175.

Kenyon, S., Rafferty, J., Lyons, G., 2003. Social Exclusion and Transport in the UK: A Role for Virtual Accessibility in the Alleviation of Mobility-Related Social Exclusion? Journal of Social Policy, 32(3), 317-338.

Larsen, J., Urry, J. and Ashausen, K., 2006. Mobilities, Networks, Geographies. Aldershot: Ashgate.

Latham, A., 2004. Researching and Writing Everyday Accounts of the City. In: Knowles, C., and Sweetman, P., (eds.), Picturing the Social Landscape: Visual Methods and the Sociological Imagination. London and New York: Routlege, pp117131.

Latham, A., 2003. Research, performance, and doing human geography: some reflections on the diary-photograph, diary-interview method. Environment and Planning A, 35, 1993-2017.

Laurier, E., (2002). Notes on dividing the attention of a car driver. Team Ethno Online.

Laurier, E. Philo, C., 2006. Possible Geographies: A Passing Encounter in a Café. Area, 38, 353-63. 
Licoppe, C, Smoreda, Z., 2005. Are social networks technologically embedded? Ho networks are changing today with changes in communication technology. Social Networks, 27, 317-335.

Livingstone, S., 2010. Taking risky opportunities in youthful content creation: teenagers' use of social networking sites for intimacy, privacy and self expression New Media and Society, 10(3), 393-411.

Lyons, G., Farag, S. Haddad, H., 2008a. The substitution of communications for travel? In: Ison, S. and Rye, T., (eds.), The Implementation and Effectiveness of Transport Demand Management measures: An International Perspective. Ashgate, 211-232.

Lyons, G, Holley, D., Jain, J., 2008b. The Business of Train Travel. In: Hislop, D, (ed.), Mobility and Technology in the Workplace. Routledge: London.

Lyons, G, Jain, J, Holley, D,. 2007. The Use of Travel Time by Rail Passengers in Great Britain. Transportation Research Part A, 41(1), 107-120.

Nationalrail, 2009. Joint us on Twitter and Facebook. Retrieved (September 24, 2009) from http://www.nationalrail.co.uk/passenger_services/social-networking.html.

Palfrey, J., \& Gasser, U., 2008. Born digital: Understanding the first generation of digital natives. New York: Basic Books. 
RAC, 2009. Red Funnel Launces Twitter Service. Retrieved (September 24, 2009) from http://www.rac.co.uk/know-how/motoring-news/item/2009/09/16/red-funnellaunches-twitter-service/.

Reinhart, C.J., 2008. Constructing the cafe' university: teaching and learning on the digital frontier. On the Horizon, 16(1), 13-33.

Rheingold, H., (ed). 2003. Smart Mobs: The Next Social Revolution. New York: The Perseus Book Group.

Rogers, E. M., 2003. Diffusion of innovations. New York: Free Press.

Schivelbusch, W., 1980. The Railway Journey Trains and Travel in the 19th Century. Blackwell, Oxford.

Schwanen, T., 2008. Managing uncertain arrival times through sociomaterial associations. Environment and Planning B: Planning and Design, 35, 997-1011.

Schwanen, T., and Kwan, M-P., 2008. The Internet, Mobile Phone and Space-Time Constraints. Geoforum 39(3), 1362-1377.

Skinner, C., 2003. Running round in Circles: Coordinating Childcare, Education and Work. The Policy Press: Bristol. 
Tillema, T., Dijst, M., Schwanen, T., 2008. Electronic communication in social networks and implications for travel. Revised paper accepted for presentation at the $87^{\text {th }}$ TRB meeting, January $13-17$, Washington, DC.

Townsend, A., 2002. Life in the Real Time City: Mobile Telephones and the Urban Metabolism. Journal of Urban Technology, 7(2) 85-104

Urry, J., 2004. Connections. Environment and Planning D: Society and Space, 22, 27-37.

Von Hippel, E., 2005. Democratizing Innovation. Cambridge: MIT Press. 


\section{Footnotes}

${ }^{1}$ It should be noted that the study successfully went through the ethical review process at the University of the West of England.

${ }^{2}$ Participants were offered a gift voucher or cash incentive (ranging from $£ 30$ to $£ 50$ ) which was given to them in two stages - half after the completion of the diary and half after the completion of the interview.

${ }^{3}$ Both pseudonyms.

${ }^{4}$ http://www.facebook.com.

${ }^{5}$ Although this is often through personal choice, rather than requirement. ${ }^{6}$ http://ww.twitter.com.

${ }^{7}$ This also illustrates the degree to which people are perhaps in a period of transition with respect to the role technologies play in their lives and development of new cultures and etiquette around the use of ICTs.

${ }^{8}$ If Anna had been commuting by public transport, rather than by bicycle, she could have used this time through a wireless internet/email facility, although this was not discussed in the interview.

${ }^{9}$ Many employers have banned employees from using Facebook during office hours.

${ }^{10}$ The latter mechanisms suggest more regular but less extensive episodes of communication (though Facebook provides for the sharing of photos).

${ }^{11}$ http://www.ideasintransit.org. 
Figure 1: Anna's diary

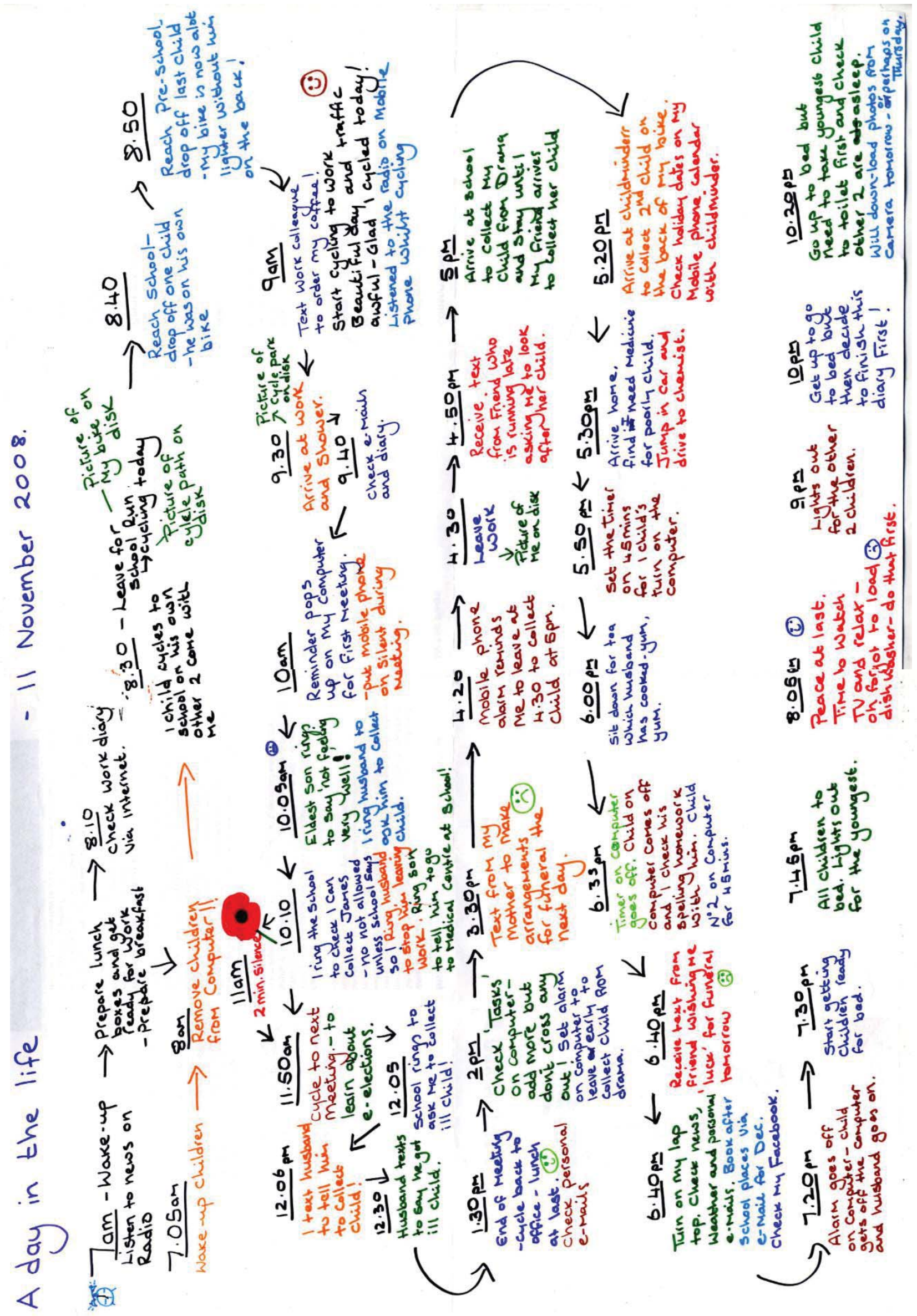


Figure 2: Ingrid's Diary

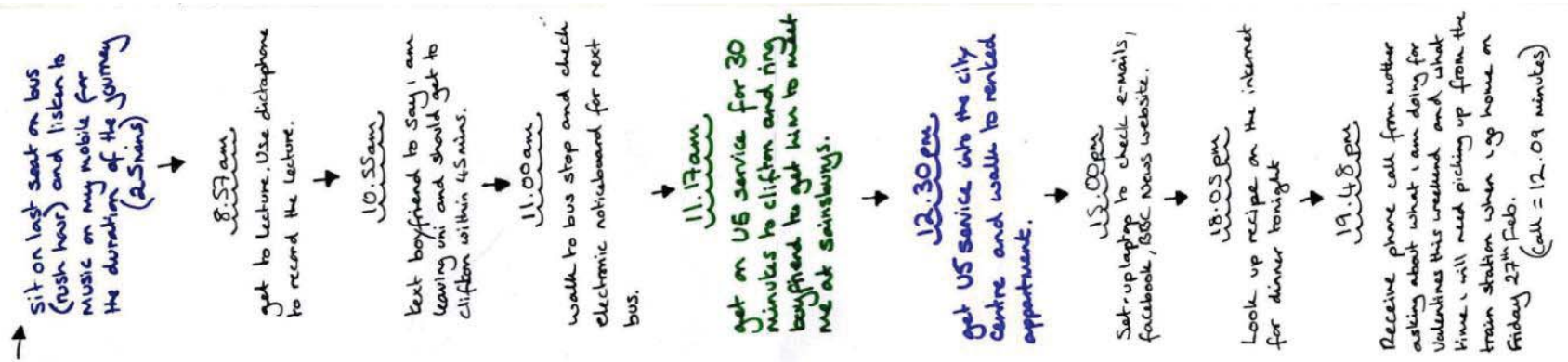

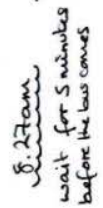

$\uparrow$

7

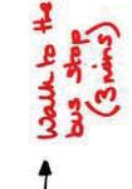

ริ)

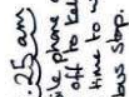

of

$\uparrow$

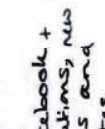

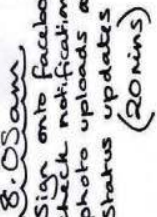

$\uparrow$

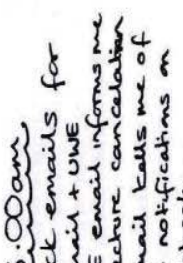

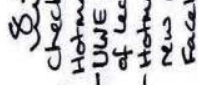

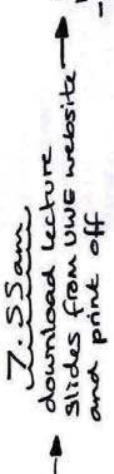

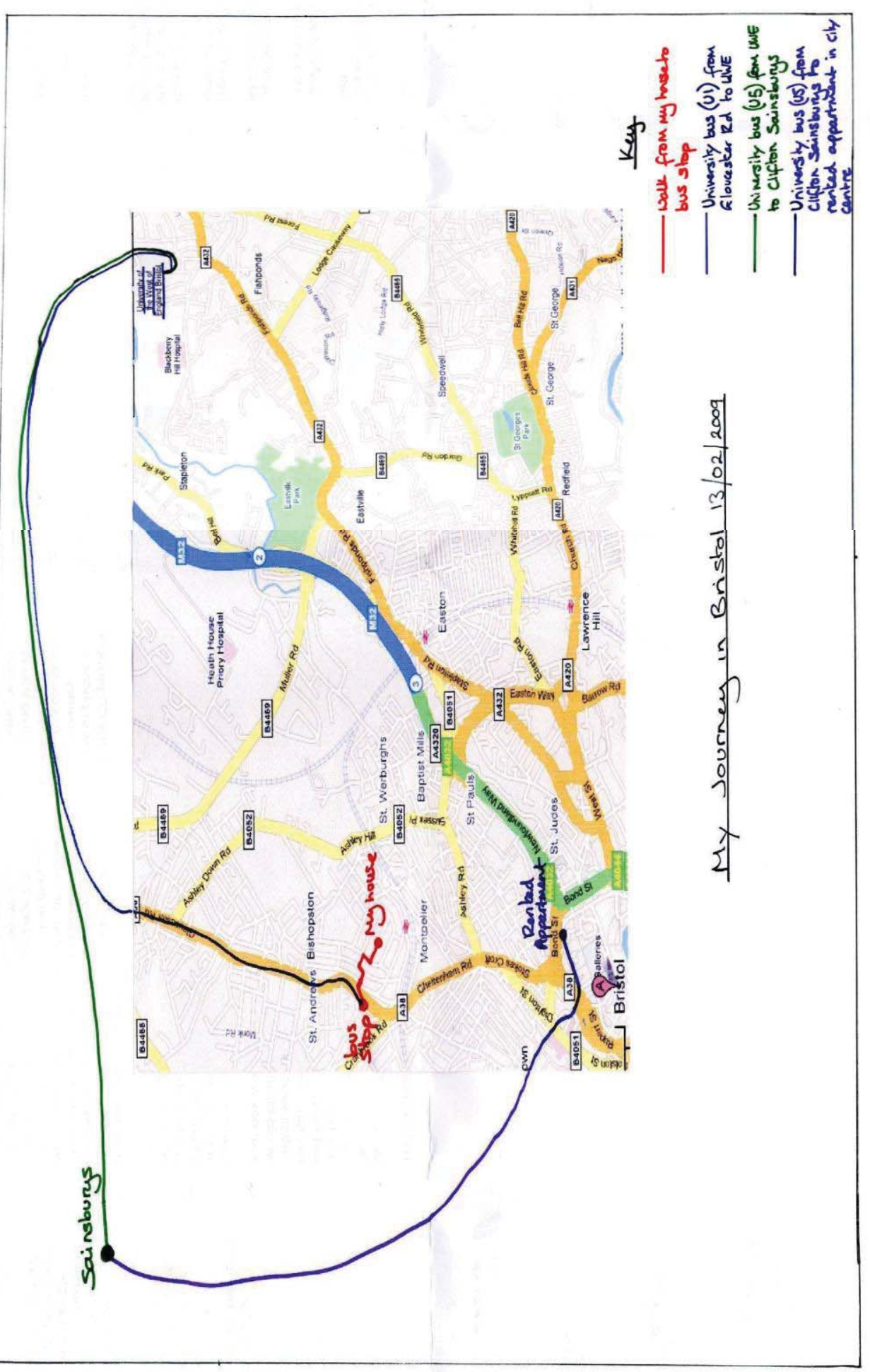

e... 
Figure 2: Ingrid's Diary

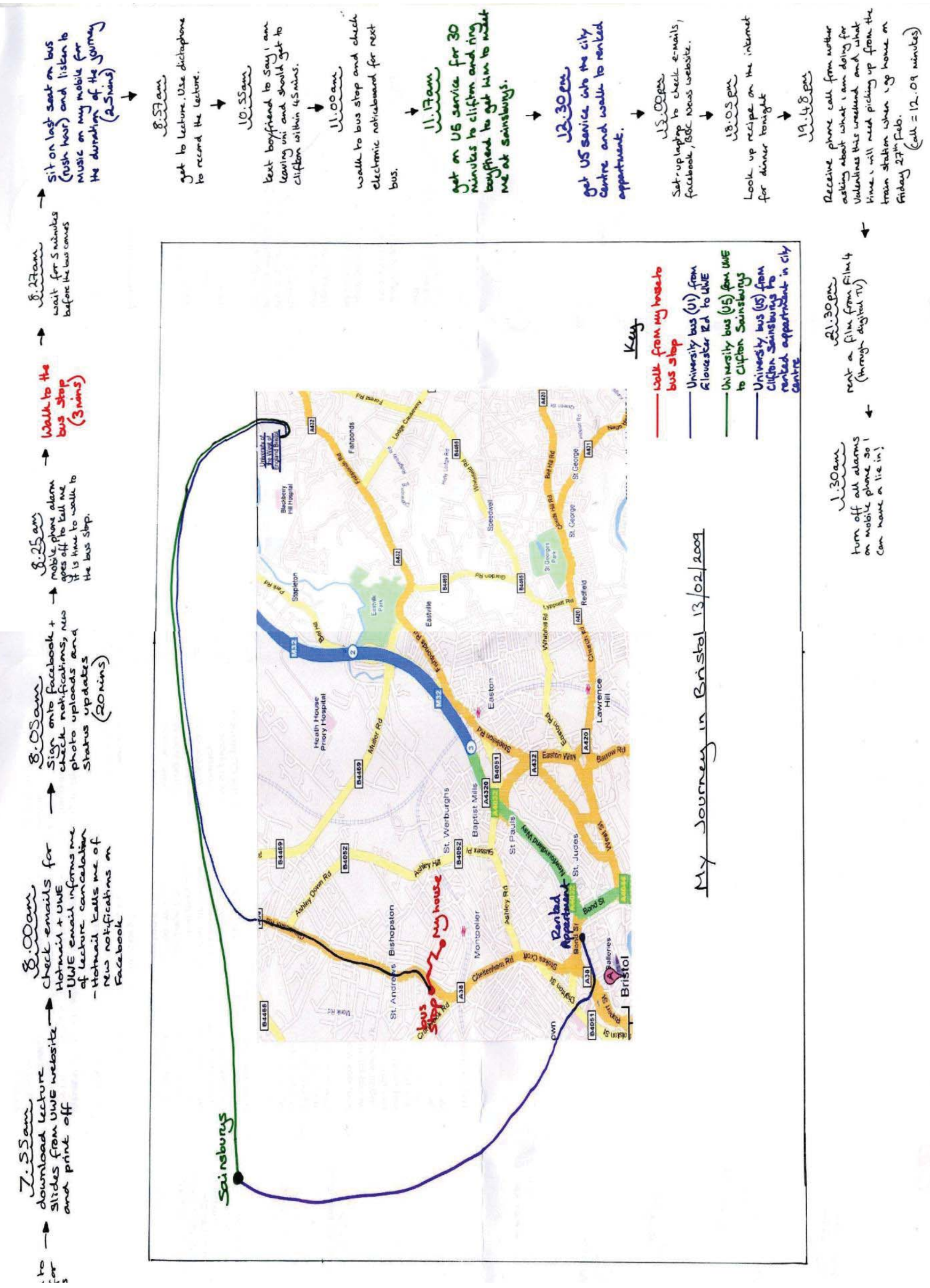


Figure 1: Anna's diary

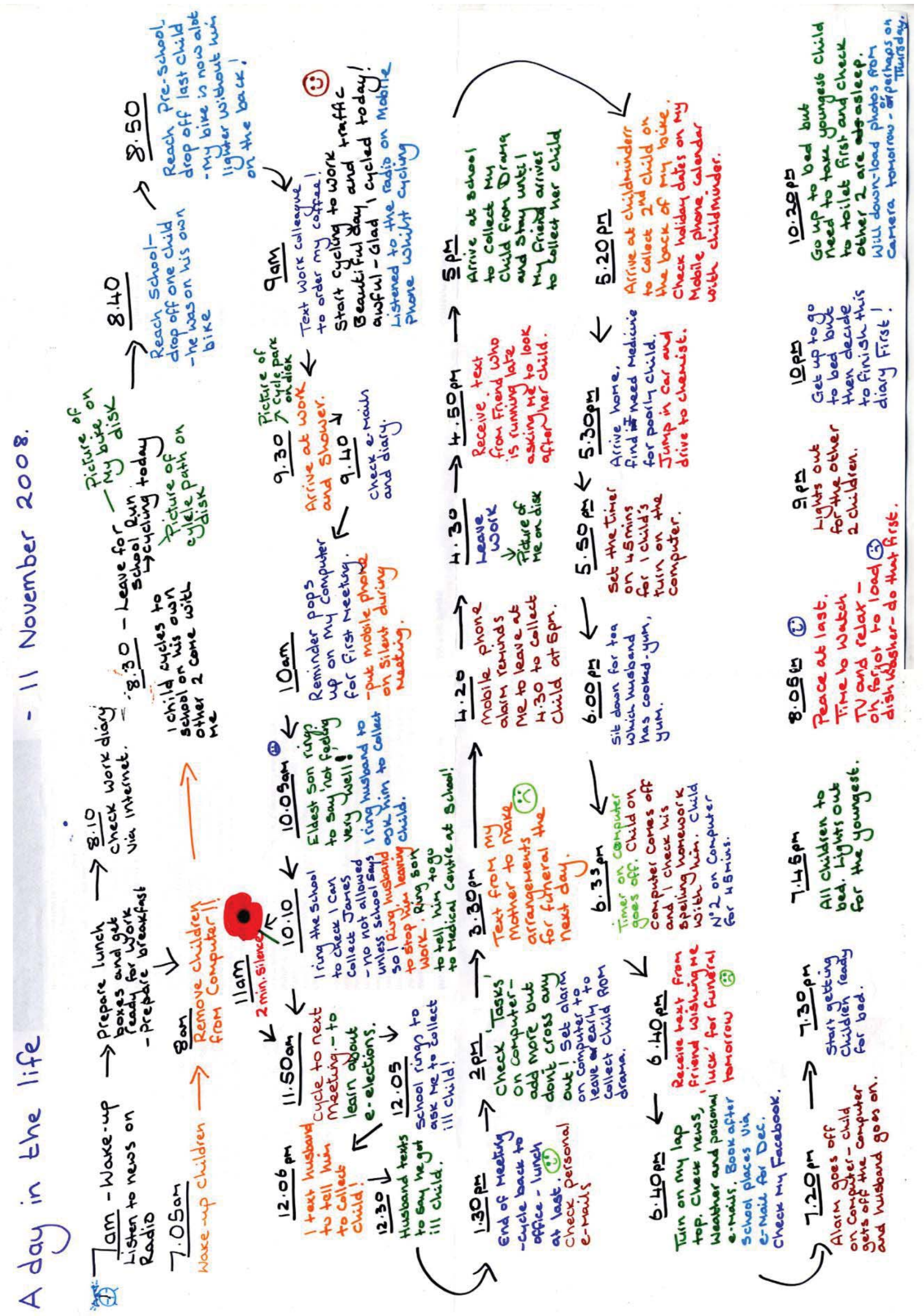

